|| ISSN(online): 2589-8698 || ISSN(print): 2589-868X ||

International Journal of Medical and Biomedical Studies

Available Online at www.ijmbs.info

NLM (National Library of Medicine ID: 101738825)

Index Copernicus Value 2019: 79.34

Original Research Article

Volume 5, Issue 8; August: 2021; Page No. 211-213

\title{
COMPLICATIONS IN DENGUE LIKE ILLNESSES
}

\section{Dr. Shaitan Singh Balai}

MD Pediatrics

Article Info: Received 14 June 2021; Accepted 05 August 2021

DOI: https://doi.org/10.32553/ijmbs.v5i8.2114

Corresponding author: Dr. Shaitan Singh Balai

Conflict of interest: No conflict of interest.

\section{Abstract}

Background: Dengue has a wide spectrum of clinical presentations, often with unpredictable clinical evolution and outcome. While most patients recover following a self-limiting nonsevere clinical course, small proportion progress to severe disease. Early recognition of dengue is challenging because the initial symptoms are often non-specific.

Methods: The hospital based study was conducted on patients presenting to paediatric hospital, who fulfilled inclusion and exclusion criteria.

Results: According to complications, in dengue positive cases, bleeding was the most common complication seen in $51.00 \%$ cases while shock, myocarditis, and convulsion were present in $34.00 \%, 3.00 \%$ and $1.00 \%$ of cases respectively. Among the dengue negative cases, $63.00 \%$ had no complication while shock and bleeding were present in $23.00 \%$ and $14.00 \%$ cases respectively.

Conclusion: It concluded that shock was most common complication.

Keywords: Complication, Fever, Dengue Like Illness

\section{Introduction}

Dengue is the most important arthropod-borne viral infection of humans. Each year there are about 50 million dengue infections and about 500,000 individuals are hospitalized with DHF, mainly in Southeast Asia. Dengue has been an urban disease but now has spread to rural areas of India as well ${ }^{1}$.

Dengue has a wide spectrum of clinical presentations, often with unpredictable clinical evolution and outcome ${ }^{2}$. While most patients recover following a self-limiting nonsevere clinical course, small proportion progress to severe disease. Early recognition of dengue is challenging because the initial symptoms are often non-specific. Viremia may be below detectable levels and serological tests confirm dengue late in the course of illness ${ }^{3}$. The key to a good clinical outcome is understanding and being alert to the clinical problems that arise during the different phases of the disease, leading to a rational approach in case management.

For severe disease (severe dengue according to the new classification or DHF/DSS according to the older classification) the case fatality rate can be as high $15 \%$ but can be decreased to $1 \%$ by early diagnosis and prompt treatment ${ }^{4}$. The overall mortality rate of $1.2 \%$ in 2007 dropped to $0.25 \%$ in 2013 . Year-wise analysis revealed that the proportion of DHF cases was about $20 \%$ in 2005, 2006 and 2008; the proportion dropped to $6.8 \%$ in 2007, 2009 and 2010.This fall probably reflected improved diagnosis and better reporting of non-hospitalized dengue cases.
For a disease that is complex in its manifestations, management is relatively simple, inexpensive and very effective in saving lives, so long as correct and timely interventions are instituted. Hence it is very important to be able to predict which patients are more likely to land up in complications. Such early prediction of adverse outcome and early detection of danger signs can help in reducing mortality and morbidity. Predictors will also help in monitoring the therapy and the course of illness in denguelike illnesses.

Since there is a paucity of literature on this, and there exist many gaps in the current understanding of such predictive factors, this study is being planned to assess history, examination, and investigation based predictive factors for complications of dengue-like illnesses.

\section{Material and Methods}

Study Design:Hospital-basedcross-sectional study.

\section{Inclusion criteria}

All the patients admitted to Paediatric ward with-

1. Age 3 months to 14 years.

2. A history of fever as given by the patient or parents or a documented fever $>38$-degree Celsius in the first 24 hours after admission.

3. Thrombocytopenia of $<100,000$ /cubic $\mathrm{mm}$ as documented in the automated counter within 24 hours of admission. 
4. Informed consent obtained from the guardians or relatives (Annexure A).

\section{Exclusion criteria}

1. Patients with a proven bacterial infection as the cause for thrombocytopenia and fever.

2. Patients with a pyogenic focus of infection.

3. Discharge against medical advice or referral to higher center before ascertaining the final outcome.

The study was commenced after obtaining clearance from the institutional ethical committee. Written consent was taken from the parents and those who were not willing

excluded from the study. Patients presenting to paediatric hospital, who fulfilled inclusion and exclusion criteria were enrolled for the study. A comprehensive history taking, physical examination, and lab investigations were carried out and data were collected in pre-designed proforma.

\section{Data Analysis:}

Data was recorded as per Performa. The data analysis was computer based; SPSS-22 was used for analysis. For categoric variables chi-square test was used. For continuous variables independent samples's $t$-test was used. $p$-value $<0.05$ was considered as significant.

\section{Observations}

Table 1: Distribution of Cases According to Age Group (years)

\begin{tabular}{|l|l|l|}
\hline \multirow{2}{*}{ Variable } & \multicolumn{1}{|c|}{ Dengue } \\
\cline { 2 - 3 } & Negative $(\mathrm{n}=100)$ & Positive $(\mathrm{n}=100)$ \\
\hline Age & $10.16 \pm 3.26$ & $10.39 \pm 2.51$ \\
\hline Male : Female & $67: 33$ & $64: 36$ \\
\hline
\end{tabular}

Mean age was $10.16 \pm 3.26$ year in dengue negative cases and $10.39 \pm 2.51$ year in dengue positive cases. This difference was found statistically insignificant $(\mathrm{p}>0.05)$. Male patients were more than the female patients. This difference was found statistically insignificant $(\mathrm{p}>0.05)$.

Table 2: Distribution of Cases According to Complication

\begin{tabular}{|c|c|c|c|c|}
\hline \multirow[t]{3}{*}{ Complication } & \multicolumn{4}{|c|}{ Dengue } \\
\hline & \multicolumn{2}{|c|}{ Negative } & \multicolumn{2}{|c|}{ Positive } \\
\hline & No. & $\%$ & No. & $\%$ \\
\hline Bleeding & 14 & 14.00 & 51 & 51.00 \\
\hline Myocarditis & 0 & - & 3 & 3.00 \\
\hline Shock & 23 & 23.00 & 34 & 34.00 \\
\hline Convulsion & 0 & - & 1 & 1.00 \\
\hline No Complication & 63 & 63.00 & 11 & 11.00 \\
\hline Total & 100 & 100.00 & 100 & 100.00 \\
\hline
\end{tabular}

$\mathrm{P}$-value $=0.001$

According to complications, in dengue positive cases, bleeding was the most common complication seen in $51.00 \%$ cases while shock, myocarditis, and convulsion were present in $34.00 \%, 3.00 \%$ and $1.00 \%$ of cases respectively. Among the dengue negative cases, $63.00 \%$ had no complication while shock and bleeding were present in $23.00 \%$ and $14.00 \%$ cases respectively.

On applying the chi-square test, the difference was found statistically highly significant $(\mathrm{p}<0.001)$.

\section{Discussion}

Dengue is a major international health concern that is prevalent in tropical and sub-tropical countries. Since the first confirmed case of dengue in India, during the 1940s, intermittent reports from Delhi, Ludhiana, Mangalore, Vellore and from other states have been published. The diagnosis is by clinical profile but they can present with varied manifestation ${ }^{5-6}$.

There is a steady increase in the outbreak of dengue fever over the years and so among children. This is due to the rapid urbanization with unplanned construction activities and poor sanitation facilities contributing fertile breeding grounds for mosquitoes. Due to an increase in the awareness among health care professionals following the initial epidemic and the availability of diagnostic tests have contributed to the increased diagnosis ${ }^{7}$.

A outbreak of dengue fever during pre-monsoon and monsoon season reported due to stagnation of water after a bouts of rainfall which facilitate vector breeding. This highlight the preventive measures against dengue fever should be taken during water stagnation periods after the initial bouts of rainfall and at the end of monsoon.

In our study mean age was $10.16 \pm 3.26$ year in dengue negative cases and $10.39 \pm 2.51$ year in dengue positive cases. This difference was found statistically insignificant ( $p>0.05$ ). Male patients were more than the female patients. This difference was found statistically insignificant $(p>0.05)$. This may be due to out-door activities of these children, where chances of getting bitten by mosquitoes are more. Similar finding was observed in other studies ${ }^{8-10}$. 
Boys were slightly more affected then girls were also observed by Selvan et $\mathrm{al}^{10}$ and Sahana et $\mathrm{al}^{9}$ and similar pattern was seen in the retrospective analysis of the 2006 North Indian Dengue outbreak ${ }^{14}$. This may be due to outdoor activities of these children, where chances of getting bitten by mosquitoes are more.

According to complications, According to complications, in dengue positive cases, bleeding was the most common complication seen in $51.00 \%$ cases while shock, myocarditis, and convulsion were present in $34.00 \%, 3.00 \%$ and $1.00 \%$ of cases respectively. Among the dengue negative cases, $63.00 \%$ had no complication while shock and bleeding were present in $23.00 \%$ and $14.00 \%$ cases respectively.

Raj et $\mathrm{al}^{11}$ observed that shock was the most common and difficult to treat complication despite appropriate fluid management in accordance with WHO regimen. 20(10.2\%) children had shock, of which 7 were refractory to fluid therapy and blood products (whole blood, packed cell volume, FFP) given as indicated.

\section{Conclusion}

It concluded that shock was most common complication.

\section{References}

1. Tripathi P, Kumar R, Tripathi S, Tambe J, Venkatesh V. Descriptive epidemiology of dengue transmission in Utta Pradesh. Ind Pediatr 2008; 45(4):315.

2. Halstead SB. More dengue, more questions. Emerg Infect Dis 2005; 11(5):740-41.

3. Ramos MM, Tomashek KM, Arguello DF, Luxemburger C, Quinones L et al. Early clinical features of dengue infection in Puerto Rico. Transactions of the Royal Society of Trop Med Hygiene 2009; 103(9):878-84.

4. Chaudhary R, Khetan D, Sinha S, Sinha P, Sonker A et al. Transfusion support to dengue patients in a hospital base blood transfusion service in North India. Transfusion and Apheresis Sci 2006;3 5(3);239-44.

5. Padibidri VS, Adhikari P, Thakare JP, Ilkal MA, Joshi GD, Pereira P, et al. The 1993 epidemic of dengue fever in Mangalore, Karnataka State, India. Southeast Asian J Trop Med Public Health. 1995;26:699-704.

6. Cherian T, Ponnuraj E, Kuruvilla T, Kirubakaran C, John TJ, Raghupathy P. An epidemic of dengue hemorrhagic fever and dengue shock syndrome in and around Vellore. Indian J Med Res. 1994;100:516.

7. Gubler DJ. Dengue and dengue hemorrhagic fever. Clin Microbiol Rev. 1998;11:480-96.

8. Mittal H, Faridi MM, Arora SK, Patil R. Clinicohematological profile and platelet trends in children with dengue during 2010 epidemic in north India. Indian J Pediatr. 2012;79:467-71.

9. Sahana KS, Sujatha R. Clinical profile of dengue among children according to revised WHO classification: analysis of a 2012 outbreak from Southern India. Indian J Pediatr 2015;82:109-13.

10. Selvan T, Nagaraj MV, Saravanan P, Somashekar. A study of clinical profile of dengue fever in children. Int J Contemp Pediatr 2017;4:534-7.

11. Raj AS, Munshi S, Shah BH. A study on clinical presentation of dengue fever in Children. IJMSR, 2016; 2272-8. 